\author{
Georg Royl \\ Juri Katchanov \\ Frank Stachulski \\ Jörg Schultze \\ Christoph J. Ploner \\ Matthias Endres
}

\section{Diagnostic pitfall: wound botulism in an intoxicated intravenous drug abuser presenting with respiratory failure}

\author{
Accepted: 6 March 2007 \\ Published online: 29 March 2007 \\ (C) Springer-Verlag 2007
}

Sir: Wound botulism has gained importance because of rising occurrence among injecting drug users (IDUs) in the United Kingdom and United States over the past 20 years [1-3] and recently also in Germany [4]. The causative organism is Clostridium botulinum, an anaerobic, gram-positive, spore-forming bacterium. We report a case of wound botulism initially misdiagnosed as drug intoxication.

A 30-year-old female IDU was admitted to the emergency department because of rapidly progressing dyspnea. She was intubated and transferred to the medical ICU. Toxicological screening revealed an intake of flunitrazepam, methadone, and cocaine, and the initial diagnosis was respiratory failure due to intoxication. A formal neurological examination of the patient, who was still ventilated on day 3 , revealed high-grade flaccid tetraparesis, facial diplegia, and bilateral ptosis. Pupils were dilated and did not react to light. Eye movements were conjugate with slowed saccades and vertical gaze paralysis. There was generalized areflexia with negative Babinski signs and no sensory deficits. Nonverbal communication (via discrete hand squeezing and minimal head movements) was normal. There were multiple scarred syringe abscesses at both legs, and one smaller florid abscess in the right groin. Nerve conduction studies revealed strongly reduced motor action potential amplitudes with normal sensory nerve action potentials. Repetitive stimulation of several peripheral nerves showed no decrement or increment. Cerebrospinal fluid examinations on days 3,6 , and 28 revealed normal cell counts, protein and lactate levels. The clinical syndrome of mydriasis, cranial nerve palsies, and flaccid tetraparesis led to the diagnosis of wound botulism. The diagnosis was confirmed on day 6 after admission by a positive mouse bioassay, which revealed subtype botulinum toxin A. The patient was treated with polyvalent antitoxin and penicillin G. The florid abscess in the groin was incised and drained. C. botulinum could not be cultured in the abscess tissue. The patient needed ventilatory support and intensive care for 3 months. She was then transferred to a rehabilitation clinic where she slowly recovered motor functions. After 6 months she was able to walk again without assistance and was discharged into ambulatory care.

Wound botulism is caused by the toxin of $C$. botulinum which presynaptically blocks the release of acetylcholine from cholinergic nerves, predominantly at the neuromuscular junction. The anaerobic environment of a syringe abscess together with the tissue damage caused by citric acid (commonly used as solvent by IDUs) is considered to favor wound botulism [1]. Clinical features involve dyspnea, dysphonia, mydriasis, diplopia, dysphagia, and descending paralysis [5]. Mouse bioassay studies and/or isolation of C. botulinum from wound cultures are required for diagnosis.

The diagnostic pitfall in our case was the presence of high blood levels of a benzodiazepine (which causes slow saccades), methadone, and cocaine (which causes mydriasis), resulting in delayed diagnosis and treatment. Wound botulism should be considered in IDUs presenting with respiratory failure. Even in the presence of alternative causes of respiratory insufficiency clinicians should have a high index of suspicion for wound botulism in IDUs.

\section{References}

1. Akbulut D, Dennis J, Gent M, Grant KA, Hope V, Ohai C, McLauchlin J, Mithani V, Mpamugo O, Ncube F, Souza-Thomas L (2005) Wound botulism in injectors of drugs: upsurge in cases in England during 2004. Euro Surveill 10:172-174

2. Passaro DJ, Werner SB, McGee J, MacKenzie WR, Vugia DJ (1998) Wound botulism associated with black tar heroin among injecting drug users. JAMA 279:859-863

3. Mulleague L, Bonner SM, Samuel A, Nichols P, Khan M, Shaw S, Gruning $\mathrm{T}$ (2001) Wound botulism in drug addicts in the United Kingdom. Anaesthesia 56:120-123

4. Alpers K, van Treeck U, Frank C (2005) Outbreak of wound botulism in injecting drug users in Germany, October-December 2005 Euro Surveill 10:E051215

5. MacDonald KL, Rutherford GW, Friedman SM, Dietz JR, Kaye BR, McKinley GF, Tenney JH, Cohen ML (1985) Botulism and botulism-like illness in chronic drug abusers. Ann Intern Med 102:616-618

G. Royl · J. Katchanov · F. Stachulski • J. Schultze · C. J. Ploner · M. Endres ( Charité Universitaetsmedizin Berlin,

Department of Neurology, Charitéplatz 1, 10117 Berlin, Germany e-mail: matthias.endres@charite.de Tel.: +49-30-450560257

Fax: +49-30-450560932 